\title{
Developing the Journal as a Place for Sharing Frontier and High-Quality Research in STEM Education
}

\section{Yeping $\mathbf{L i}^{1}$}

Published online: 24 November 2021

(c) The Author(s), under exclusive licence to Springer Nature Switzerland AG 2021

\begin{abstract}
With the completion of its first three years (2018 to 2020), the Journal for STEM Education Research has made steady progress with its commitment to promote high-quality research in STEM education. In this editorial, I specifically share the journal's performance in terms of its publication growth, access and citation metrics, and possible development in the future. The review reveals the journal's continued development in publications and impact with on-going strong support from researchers and readers worldwide.
\end{abstract}

Keywords Citation · Impact · Journal publication $\cdot$ Research $\cdot$ Scholarship $\cdot$ STEM education

\section{Introduction}

The publication of a combined two issues for the first volume in December 2018 marked the official launch of the Journal for STEM Education Research (J-STEM). At the end of 2020, the journal had published three volumes. Along with the rapid development of STEM education internationally, the journal has also evolved with increased recognition in the field. Here, I will briefly review and reflect on (1) the journal's publication growth over the first three years, (2) the journal's publication performance during these three years, and (3) the journal's further development to promote STEM education research.

Yeping Li

yepingli@tamu.edu

1 Texas A\&M University, College Station, TX 77843-4232, USA 


\section{The Journal's Publication Growth over the First Three Years (December 2018 to December 2020)}

It is important to attract and publish many high-quality papers when starting and establishing a new journal. The journal's publication performance can be measured in part by the number of articles published each year and how well these publications are received and accessed by scholars in the field. In this section, I will focus on the number of articles published in the journal's first three years.

The J-STEM published a total of 39 articles over the past three years, thus averaging 13 articles per year. Figure 1 shows the journal's steady publication growth from December 2018 to December 2020. In December 2018, one combined issue was published as volume 1 with nine articles. In 2019, two issues were published as volume 2 with a total of 11 articles. In 2020, three issues were published as volume 3 with a total of 19 articles. It is clear that the journal had a steady increase in publishing more issues and articles since December 2018.

\section{The Journal's Publication Performance During the First Three Years}

One critical aspect of an academic journal's performance is the impact of the journal as a whole. There are different measures that can be used in a professional field to assess a journal's impact (e.g., peer evaluation, recognition within the field, and inclusion by various indexing services). One commonly valued indicator is the number and type of indexing services that include the journal. However, with the limited number of publications that the journal has had so far, Springer has not yet applied for this journal for possible inclusion considerations by prestigious indexing services such as Elsevier's Scopus and Clarivate's Social Sciences Citation Index. Thus, we need to look at other measures to learn about the journal's publication impact to date.

One way to do this is to examine how well the journal's publications are received and accessed by scholars in the field. Figure 2 shows the total number of times

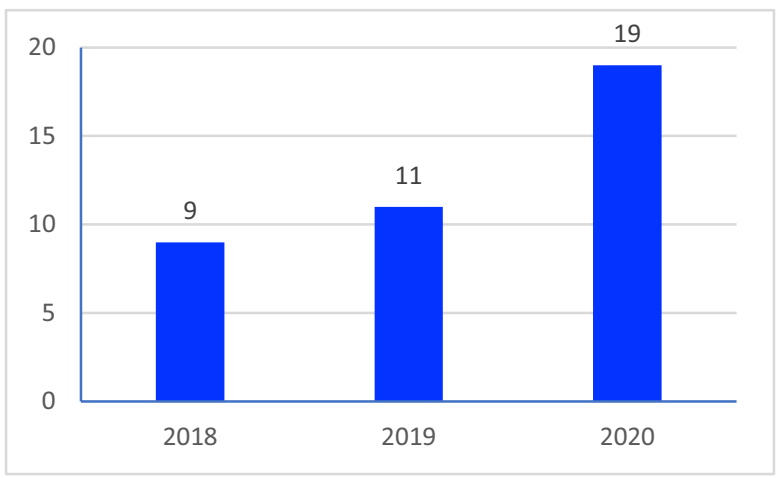

Fig. 1 Number of publications by year 


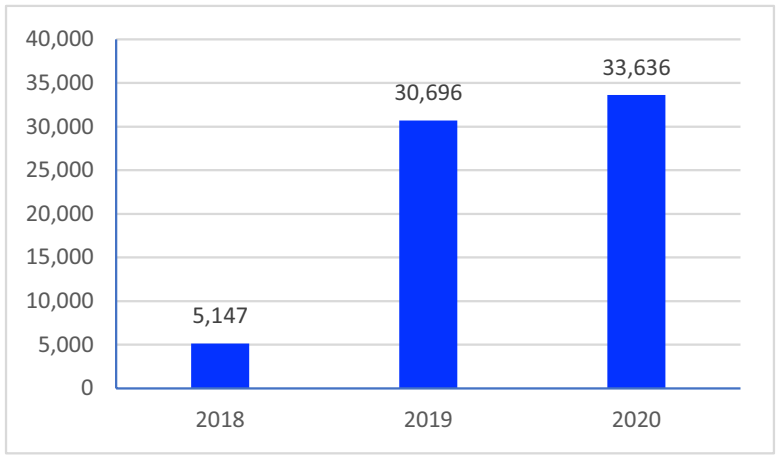

Fig. 2 Number of accesses by year (Source: Springer).

Note: Accesses are defined as the number of times full text or PDF versions of articles are accessed directly from the journal website and SpringerLink. Downloads are defined as HTML, LookInside, PDF, and Epub clicks. Please note that accesses do not include article downloads from mirror databases such as PubMed Central

the journal's publications were accessed by year. It is clear that the publications attracted increasing numbers of views and downloads over the first three years, with a total of 5,147 accesses in 2018, 30,696 accesses in 2019, and 33,636 accesses in 2020. I should note that Springer made all publications open access to everyone in 2018 and 2019. Thus, with only nine articles published in December 2018, these publications still received 5,147 accesses in less than a month in 2018. This leads to an average of about 572 accesses per article. Adding the 11 article publications in 2019 (5 articles as issue 1 in April 2019, and 6 articles as issue 2 in December 2019), the journal had a total of 30,696 accesses in 2019. It averages out at 1,535 accesses per article in 2019. The dramatically increased number of accesses from 2018 to 2019 indicates that the journal's publications were well received and downloaded with a fast increasing trend.

Because this journal is not an open-access journal, but subscription based (Li, 2018), the journal's publications are no longer freely accessible since 2020, except for some publications with special arrangements such as those published as Open Access with a fee payment. Thus, it is understandable that access to the journal's publications has been restricted since 2020. The number of accesses in 2020 $(33,636$, in comparison to 30,696 in 2019) does not show a similar rate of increase as the case from 2018 to 2019 . Nevertheless, it is very reassuring that the number of accesses in 2020 was still more than the number in 2019. The result suggests that the journal's publications were clearly sought after by many readers and researchers even after the free access to the journal's publications was turned off.

In addition to the total number of publication accesses, it is also important to find out where accesses took place. Table 1 shows the ranking of five continents in terms of accumulative accesses over the years. The Americas had the largest number of accesses, followed by Asia, Europe, Oceania, and Africa. While the United States (in Americas) had dramatically more accesses $(75 \%$ of all accesses) than all other countries/regions, several other countries/regions 
Table 1 Rank of five continents that accessed the journal's publications

\begin{tabular}{ll}
\hline Rank & $2018-2020$ \\
\hline 1 & Americas \\
2 & Asia \\
3 & Europe \\
4 & Oceania \\
5 & Africa \\
\hline
\end{tabular}

Source: Google analytics.

also showed some noticeable access activity such as Australia (2\%), India (2\%), Indonesia (2\%), Philippines (2\%), Canada (1\%), China (1\%), and the UK $(1 \%)$. It clearly indicates the journal's international reach to readers and scholars interested in STEM education research around the world.

To learn further about readers' interest, it would be helpful to identify and examine some most-accessed articles as I did in other reviews (e.g., Li, 2020; Li et al., 2019a). However, this journal has only a few articles published with open access. The variations in accessibility across different articles won't allow us to gain a clear view about readers' interest. Alternatively, we can take a closer look at some of the most-cited publications to learn more about researchers' interest and the journal's publication citation trends.

Table 2 shows the top 12 most-cited publications in descending order. As there are only a total of 39 publications in 2018-2020, 12 of these 39 publications (about $31 \%$ ) have been cited eight times or more (with an average of about 14 times) over two years. The result provides a clear indication that many of the journal's publications have been well cited. Moreover, among these 12 mostcited publications, four were published in 2018, five in 2019, and three in 2020. As the relatively recent publications are also being cited frequently, the result suggests a trend of increased attention from the field to this young journal's high-quality publications.

Taking a closer look at these publications' topics, the vast majority of the 12 most-cited publications in 2018-2020 are clearly about STEM rather than one of the component disciplines of STEM. The result suggests that the journal is being recognized for its focus as originally designed on interdisciplinary research in STEM education ( $\mathrm{Li}, 2018)$.

Table 2 also shows that the vast majority (10) of these 12 most-cited publications were contributed by scholars from the United States. While this result suggests the active and quality contributions to STEM education scholarship by U.S. scholars, it is great to find that two of these most-cited publications are contributed by scholars from outside of the United States (i.e., Hong Kong, China, and mainland China). The result provides an excellent indication that STEM education research is also growing in other education systems. We certainly hope to have more and more high-quality publications contributed by researchers from 


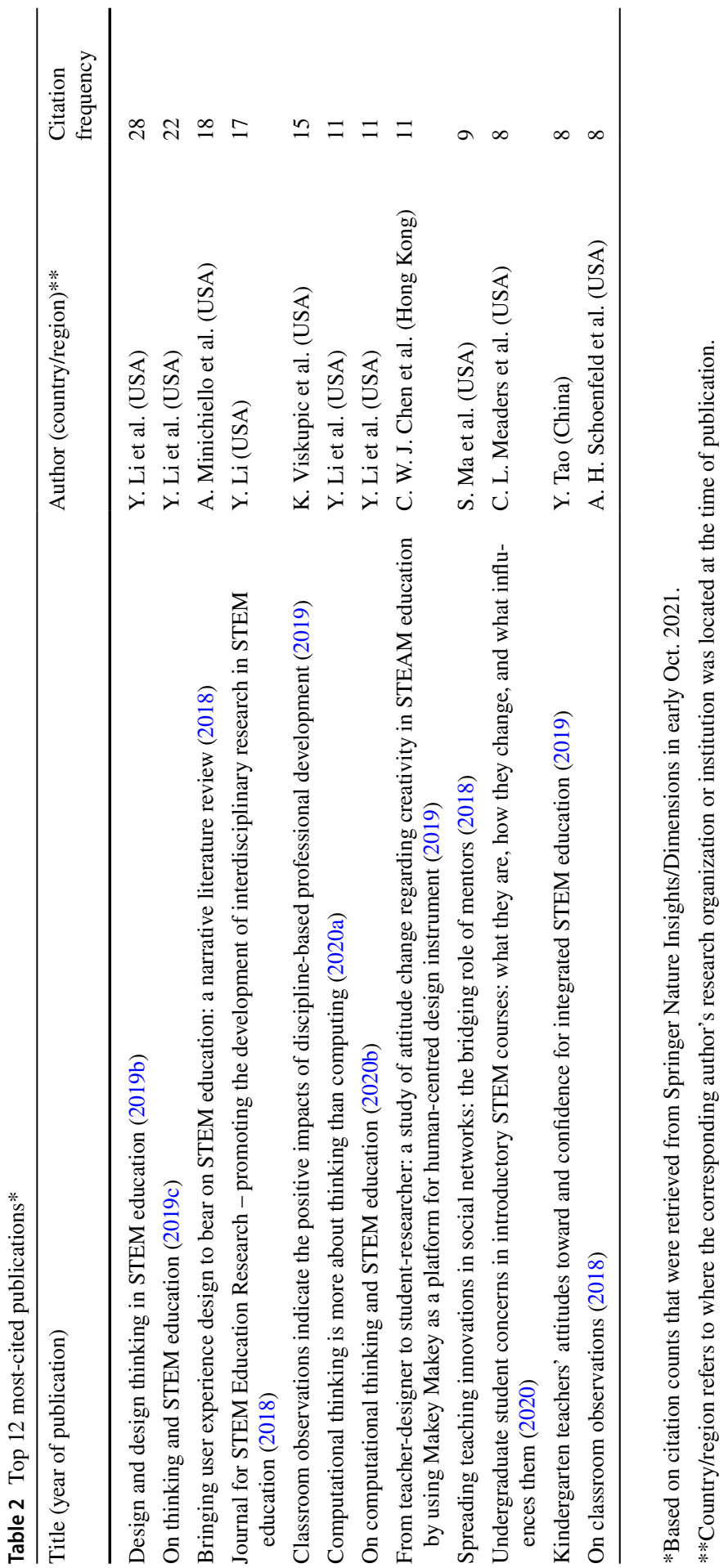


many more different education systems to support the development of STEM education worldwide.

\section{The Journal's Further Development to Promote Interdisciplinary Research in STEM Education}

The J-STEM was established in 2018 as a frontier and forward-looking research journal to promote the development of interdisciplinary research in STEM education as a distinct field ( $\mathrm{Li}, 2018)$. The past three years of development has been a great start for the journal allowing it to gain a gradual recognition internationally in terms of its growing number of publications, international reach, and publication impact. It is important for the journal to keep up the good work with ongoing support from researchers and readers around the world. At the same time, it is also important to identify opportunities for further development to promote STEM education research. Here, I would like to share and discuss two aspects below.

The first aspect relates to the type of articles that the journal publishes. The $J$-STEM publishes five types of articles: research articles, research reviews, research briefs, book reviews, and editorials. Readers can find all these types of article publications on the journal's website (https://www.springer.com/journal/ 41979). On examining the journal's publications in terms of article types, we find that the vast majority of published articles are research articles (called "original paper" in the first two years, 31 out of 39 publications from 2018 to 2020, about $79 \%$ ). This is important for J-STEM as a research journal. At the same time, one can notice that there are only two research reviews (about 5\%) published in the first three years. The situation indicates a clear shortage of research reviews. To develop the journal as a place for sharing frontier research in STEM education, it is important to publish many more research reviews that can not only summarize up-to-date research development, but also suggest possible research development directions for the field. The journal would strongly encourage submission of many more research reviews.

The second aspect relates to ways of publishing that can promote collective contributions. So far, the journal has been focusing on individual article publications, but not on special issues. Publishing special issues can provide opportunities for researchers to identify cutting-edge and important topic areas that call for special and collective research attention and contributions. It is an important way of promoting research as used by many journals in different fields. Thus, this journal also encourages international STEM education researchers to consider the possibility of collaborating and proposing special issues for consideration. At this time, one special issue is being established to call for manuscript contributions (see https://www.springer.com/journal/41979/updates/19614656). This special issue aims to bring researchers together to discuss and share frontier research about various new tools and environments in STEM education that are made possible with emerging technologies such as artificial intelligence, robots, 
augmented reality, and intelligent tutoring systems. It is designed to contribute new insights on curriculum design and pedagogical approaches for making STEM education the foundation of accessible, relevant, and equitable learning in keeping with contemporary digital advancements. This call for contributions may also provide some general ideas for interested researchers about possible components needed for preparing and proposing a special issue. Once a proposal for a special issue is received by the journal, a review process will be carried out before possible acceptance and next steps.

I expect the journal to continue to grow to further support STEM education research and development as a distinct field. I certainly realize that the journal's success originates from the great contributions and support from numerous authors, scholars, and readers around the world. Here, I want to take this opportunity to thank everyone for all the support and contributions to this young journal. Without that on-going support, this journal would not be able to achieve what we all can be proud of. It is the contributions made by all authors, reviewers, members of the journal's editorial board, and staff members at Springer that allow the journal to pursue its commitment to quality. The on-going access and citations of the journal's publications, made by international researchers and readers, are great indicators of the quality of this journal's publications and how they are being valued for promoting STEM education research around the world.

Thank you all for making the journal an international place for sharing frontier and high-quality research in STEM education.

Acknowledgements The author would like to thank Puja Dayal and other staff at Springer Nature for providing relevant data and valuable feedback on an earlier version of this editorial. Thanks also go to the journal's editorial board members for their valuable feedback to improve this editorial.

Data availability The data and materials used and analyzed for the editorial were provided by Springer or were these articles published in this journal. Journal article information is accessible at the journal's website (https://www.springer.com/journal/41979).

\section{Declarations}

Competing Interests Not applicable, as this is a single-authored article.

\section{References}

Chen, C. W. J., \& Lo, K. M. J. (2019). From teacher-designer to student-researcher: A study of attitude change regarding creativity in STEAM education by using Makey Makey as a platform for humancentred design instrument. Journal for STEM Education Research, 2(1), 75-91. https://doi.org/10. 1007/s41979-018-0010-6

Li, Y. (2018). Journal for STEM education research - Promoting the development of interdisciplinary research in STEM education. Journal for STEM Education Research, 1, 1-6. https://doi.org/10. 1007/s41979-018-0009-z

Li, Y. (2020). Six years of development in promoting identity formation of STEM education as a distinct field. International Journal of STEM Education, 7, 59. https://doi.org/10.1186/s40594-020-00257-w 
Li, Y., Froyd, J. E., \& Wang, K. (2019a). Learning about research and readership development in STEM education: A systematic analysis of the journal's publications from 2014 to 2018. International Journal of STEM Education, 6, 19. https://doi.org/10.1186/s40594-019-0176-1

Li, Y., Schoenfeld, A. H., diSessa, A. A., Grasser, A. C., Benson, L. C., English, L. D., \& Duschl, R. A. (2019c). On thinking and STEM education. Journal for STEM Education Research, 2(1), 1-13. https://doi.org/10.1007/s41979-019-00014-x

Li, Y., Schoenfeld, A. H., diSessa, A. A., Grasser, A. C., Benson, L. C., English, L. D., \& Duschl, R. A. (2019b). Design and design thinking in STEM education. Journal for STEM Education Research, 2(2). https://doi.org/10.1007/s41979-019-00020-Z

Li, Y., Schoenfeld, A. H., diSessa, A. A., Grasser, A. C., Benson, L. C., English, L. D., \& Duschl, R. A. (2020a). Computational thinking is more about thinking than computing. Journal for STEM Education Research, 3(1), 1-18. https://doi.org/10.1007/s41979-020-00030-2

Li, Y., Schoenfeld, A. H., diSessa, A. A., Grasser, A. C., Benson, L. C., English, L. D., \& Duschl, R. A. (2020b). On computational thinking and STEM education. Journal for STEM Education Research, 3(2), 147-166. https://doi.org/10.1007/s41979-020-00044-w

Ma, S., Herman, G. L., Tomkin, J. H., Mestre, J. P., \& West, M. (2018). Spreading teaching innovations in social networks: The bridging role of mentors. Journal for STEM Education Research, 1, 60-84. https://doi.org/10.1007/s41979-018-0002-6

Meaders, C. L., Lane, A. K., Morozov, A. I., Shuman, J. K., Toth, E. S., Stains, M., Stetzer, M. R., Vinson, E., Couch, B. A., \& Smith, M. K. (2020). Undergraduate student concerns in introductory STEM courses: What they are, how they change, and what influences them. Journal for STEM Education Research, 3(2), 195-216. https://doi.org/10.1007/s41979-020-00031-1

Minichiello, A., Hood, J. R., \& Harkness, D. S. (2018). Bringing user experience design to bear on STEM education: A narrative literature review. Journal for STEM Education Research, 1, 7-33. https://doi. org/10.1007/s41979-018-0005-3

Schoenfeld, A. H., Floden, R., Chidiac, F. E., Gillingham, D., Fink, H., Hu, S., Sayavedra, A., Weltman, A., \& Zarkh, A. (2018). On classroom observations. Journal for STEM Education Research, 1, 34-59. https://doi.org/10.1007/s41979-018-0001-7

Tao, Y. (2019). Kindergarten teachers' attitudes toward and confidence for integrated STEM education. Journal for STEM Education Research, 2(2), 154-171. https://doi.org/10.1007/s41979-019-00017-8

Viskupic, K., Ryker, K., Teasdale, R., Manduca, C., Iverson, E., Farthing, D., Bruckner, M. Z., \& McFadden, R. (2019). Classroom observations indicate the positive impacts of discipline-based professional development. Journal for STEM Education Research, 2(2), 201-228. https://doi.org/10.1007/ s41979-019-00015-w

Publisher's Note Springer Nature remains neutral with regard to jurisdictional claims in published maps and institutional affiliations. 